\title{
PENGARUH KECAKAPAN PERSONAL TERHADAP LITERASI SAINS SISWA
}

\author{
Siti Masfuah \\ Pendidikan Guru Sekolah Dasar \\ FKIP Universitas Muria Kudus \\ e-mail: fuah.umk@gmail.com
}

\begin{abstract}
Aimed's this research is to investigate the effect personal skills to scientific literacy. The method used was survey method with correlational approach, while the analyze used was regretion, coefficient of correlation and coefficient of determination. The population was grade VII students of SMP 1 Juwana year 2012/2013. Sampling was done by purposive random sampling. The instruments used in this research is test method to measure the ability of scientific literacy, while to measure the personal skills are observation sheet and worksheet. Based on data analyze with regression analyzation, it was found function of regression $\hat{Y}=1,006 \mathrm{X}-10,17$ withcorrelation coefficient between personal skills and scientific literacy (rxy) was 0.56, wich meant that there was a positive correlation between personal skills and scientific literacy. Moreover, the coefficient of determination was 0.31 which indicated that $31 \%$ of the personal skills was affected by scientific literacy through a linear relationship, while 69\% were influenced by other factos.
\end{abstract}

\begin{abstract}
ABSTRAK
Tujuan dari penelitian ini untuk mengetahui pengaruh kecakapan personal terhadap kemampuan literasi sains siswa.Metode penelitian yang digunakan adalah metode surveidengan pendekatan korelasional, sedangkan teknik analisis data yang digunakan dengan uji regresi, koefisien korelasi dan determinasi.Populasi penelitian ini adalah siswa SMPN 1 Juwana kelas VII tahun pelajaran 2012/2013 dengan sampel kelas VII C. Sampel tersebut diambil secara purposive random sampling.Instrumen yang digunakan dalam penelitian ini adalah instrumen tes untuk mengukur kemampuan literasi sains sebagai variabel terikat $(\mathrm{Y})$, sedangkan instrumen yang digunakan untuk mengukur kecakapan personal adalah lembar observasi dan lembar aktivitas siswa (LAS) sebagai variabl bebas (X).Berdasarkan analisis data yang telah dilakukan dengan uji regresi, didapatkan persamaan $\hat{Y}=1,006 \mathrm{X}-10,17$ dan didapatkan hasil koefisien korelasi antara kecakapan personal dengan literasi sains siswa $\left(\mathrm{r}_{\mathrm{XY}}\right)$ sebesar 0,56 yang berarti terdapat hubungan positif antara kecakapan personal dengan kemampuan literasi sains siswa. Selain itu, berdasarkan analisis data,diperoleh nilai koefisien determinasi $\left(r^{2}\right)$ sebesar 0,314 yang berarti bahwa $31 \%$ kemampuan literasi sains dipengaruhi oleh kecakapan personal, sedangkan $69 \%$ dipengaruhi oleh faktor lain.
\end{abstract}

\section{PENDAHULUAN}

Persaingan yang ketat pada era modern ini menuntut manusia untuk aktif dan kreatif mengembangkan potensi diri. Salah satu hal yang harus dilakukan adalah mengembangkan potensi melalui bidang pendidikan sains. Ilmu sains berhubungan dengan cara mencari tahu tentang alam secara sistematis, sehingga sains bukan hanya penguasaan kumpulan pengetahuan yang berupa fakta-fakta, 
konsep-konsep, atau prinsip-prinsip saja tetapi juga merupakan suatu proses penemuan. Pembelajaran sains dapat menumbuhkan kemampuan berpikir, bekerja, dan bersikap ilmiah serta mengkomunikasikannya sebagai aspek penting kecakapan hidup (Permendiknas 22 , 2006). Sains diperlukan dalam kehidupan sehari-hari untuk memenuhi kebutuhan manusia melalui pemecahan masalah-masalah yang dapat diidentifikasikan.Segala permasalahan tersebut dapat dipecahkan jika masyarakat mempunyai literasi sains (Rahayu, 2014).

Salah satu target dari pendidikan sains adalah terbentuknya masyarakat berliterasi sains (Hoolbrook \& Rannikmae, 2009). Literasi sains dianggap sebagai kunci dalam pendidikan pada usia 15 tahun apakah meneruskan belajar sains ataukah tidak (Anggraini, 2014). Siswa dikatakan berliterasi sains jika dapat menerapkan konsep sains yang dipelajari untuk diaplikasikan dan memecahkan permasalahan dalam kehidupan seharihari.Oleh karena itu, literasi semakin diperlukan agar manusia dapat bertahan dalam persiangan di abad modern ini (New Zealand Curriculum Guides, 2013).

Programme for International Student Assessment(PISA) mendefinisikan literasi sains sebagai kemampuan menggunakan sains, mengidentifikasi pertanyaan, dan menarik kesimpulan berdasarkan buktibukti dalam rangka memahami serta membuat keputusan berkenaan dengan alam dan perubahan yang dilakukan terhadap alam melalui aktivitas manusia (Bybee, 2009). Rata-rata skor literasi sains siswa Indonesia masih sangat memprihatinkan, yaitu menduduki urutan 60 dari 65 peserta pada tahun 2009 (Balitbang Kemdikbud, 2012). Dari data tersebut diketahui bahwa kemampuan literasi sains siswa Indonesia sangat memprihatinkan. Dengan demikian, guru sains harus mempunyai formula bagiamna cara mengajarkan sains dengan baik dan dapat menggali kemampuan siswa agar mempunyai literasi sains yang baik.

Rychen \& Salganik (2003) menyebutkan bahwa literasi sains searah dengan pengembangan kecakapan hidup. Pernyataan tersebut berarti bahwa keterampilan bernalar dalam konteks sosial dapat menekankan kemampuan literasi sains yang diperuntukkan bagi semua orang. Model scientific literacy menekankan perlunya keseimbangan antar berbagai kompetensi dan membutuhkan keterampilan personal dalam pengambilan keputusan sosial saintifik (Holbrook \& Rannikmae, 2007). Dengan demikian, salah faktor yang sangat berpengaruh terhadap kemampuan literasi sains adalah kecakapan personal.

Kecakapan hidup adalah kemampuan untuk menghadapi permasalahan hidup, kemudian secara kreatif mencari dan menemukan solusi untuk mengatasinya sehingga dapat survive dalam kehidupannya. Pendidikan berbasis kecakapan hidup bagi siswa adalah sebagai bekal dalam menghadapi dan memecahkan problema hidup dan kehidupan, baik sebagai pribadi yang mandiri, warga masyarakat, maupun sebagai warga negara. Salah satu tujuan dari kecakapan hidup bertujuan mengaktualisasikan potensi peserta didik sehingga dapat digunakan untuk memecahkan problema yang dihadapi. Kecakapan hidup terdiri atas kecekapan generic dan kecakpan spesifik. Kecakapan dasar yang harus dimiliki siswa adalah kecakapan personal yang mencakup tentang kecakapan memahami diri dan kecakapan berpikir (Depdiknas, 2006).

Berdasarkan uraian di atas, diperlukan penelitian untuk mengetahui pengaruh dan seberapa besar pegaruh kecakapan personal terhadap kemampuan literasi sains. Hipotesis yang diajukan 
dalam penelitian ini adalah sebagai berikut:

Ho:tidak terdapat pengaruh yang signifikan antara kecakapan personal $(\mathrm{X})$ terhadap literasi sains siswa $(\mathrm{Y})$

$\mathrm{Ha}$ : terdapat pengaruh yang signifikan antara kecakapan personal (X) terhadap literasi sains siswa (Y).

\section{METODE PENELITIAN}

Penelitian ini merupakan penelitian kuantitatif dengan pendekatan korelasional.Tujuan dari penelitian ini untuk mengetahui pengaruh kecakapan personal terhadap literasi sains.Populasi dalam penelitian ini adalah seluruh siswa kelas VII SMPN 1 Juwana ahun ajaran 2012/2013 dengan sampel kelas VII C yang diambil secara purposive random sampling karena di sekolah tersebut terdapat kelas unggulan.

Penelitian ini diawali dengan analisis masalah, perumusan tujuan penelitian, perancangan instrumen penelitian, validasi oleh para ahli, uji coba skala kecil dengan subjek 6 siswa, uji coba skala luas dengan subjek 28 siswa dan analisis data untuk menguji hipotesis. Instrumen yang digunakan adalah tes, lembar observasi dan LAS.Penelitian ini menggunakan dua variabel, yaitu variabel bebas dan variabel terikat.Variabel bebas dalam penelitian ini (X) adalah kecakapan personal dan variabel terikat (Y) adalah literasi sains.
Kecakapan personal yang diteliti meliputi sikap tanggung jawab, percaya diri, mandiri, sopan, dan disiplin yang diukur dengan instrumen lembar observasi, kemampuan menggali informasi, mengolah informasi dan mengambil keputusan diukur dengan instrumen lembar aktivitas siswa. Kemampuan literasi yang diteliti yaitu pengetahuan sains, proses sains yang meliputi kemampuan mengidentifikasi, menjelaskan, menginterpretasi dan menarik kesimpulan, serta aplikasi sains diukur dengan menggunakan instrumen tes.

Semua instrumen tersebut dianalisis dengan statistik deskriptif untuk mengetahui skor dari validator, kemudian dianalisis dengan statistik inferensial dengan uji rgresi linier sederhana, mengukur koefisien korelasi dan koefisien determinasi untuk mengetahui seberapa besar pengaruh kecakapan personal terhadap literasi sains siswa.

\section{HASIL DAN PEMBAHASAN}

Pada tahap awal, semua instrumen divalidasi oleh tiga validator (expert judgement) untuk menilai validitas dan kelayakannya.Rata-rata skor semua instrumen dari validator adalah 91,1 atau berada dalam kategori sangat valid/sangat layak (lihat Tabel 1).

Tabel 1 Validitas Instrumen Penelitian Oleh Validator

\begin{tabular}{lcccc}
\hline \multicolumn{1}{c}{ Instrumen } & Validator 1 & Validator 2 & Validator 3 & Rata-rata \\
\hline Bahan ajar & 86 & 89 & 91 & 89 \\
Silabus & 90 & 100 & 98 & 96 \\
RPP & 92 & 97 & 97 & 95 \\
Soal literasi & 89 & 94 & 93 & 92 \\
LAS & 86 & 92 & 89 & 89 \\
Lembar obserasi & 82 & 89 & 86 & 86 \\
Rata-rata & 87,5 & 93,5 & 92,3 & 91,1 \\
Kategori & sangat valid & sangat valid & sangat valid & sangat valid \\
\hline
\end{tabular}


Setelah divalidasi, semua instrumen diujicobakan kepada 6 siswa selain sampel penelitian yang masih berada dalam satu populasi.Tahap analisis data dimulai dari pengujian validitas instrumen oleh para ahli, validitas, reliliabitas, tingkat kesukatan dan daya pembeda butir soal, serta validitas dan reliabilitas instrumen lembar observasi dan LAS.Setelah tahap uji coba selesai, selanjutnya dilakukan uji normalitas dan uji hipotesis penelitian.

Sebelum uji hipotesis dilakukan, terlebih dahulu dilakukan analisis deskriptif untuk mengetahui deskriptif data setiap variabel penelitian.Deskriptif data secara lengkap dapat dilihat pada Tabel 2.

Tabel 2 Deskripsi Data Hasil Penelitian

\begin{tabular}{ccccccc}
\hline Variabel & $\begin{array}{c}\text { Skor } \\
\text { Min }\end{array}$ & $\begin{array}{c}\text { Skor } \\
\text { Max }\end{array}$ & Rata-rata & Median & Modus & $\begin{array}{c}\text { Standar } \\
\text { deviasi }\end{array}$ \\
\hline X & 51 & 82 & 71 & 73 & 77 & 8,77 \\
Y & 29 & 91 & 61 & 62 & 73 & 15,76 \\
\hline
\end{tabular}

Keterangan:

$\mathrm{X}$ : Kecakapan personal

$\mathrm{Y}$ : Literasi sains

Tahap selanjutnya, peneliti menguji hipotesis yang diawali dengan uji homogenitas dan normalitas variabel $\mathrm{Y}$ untuk mengetahui langkah uji hipotesis yang digunakan.Pengujian homogenitas dilakukan dengan menggunakan uji $\mathrm{F}$ dengan membandingkan varians terbesar dan varians terkecil. Berdasarkan analisi data, diperoleh skor $\mathrm{F}$ hitung sebesar 1,37 dan $F$ table sebesar 3,12. Dengan demikian dapat disimpulkan bahwa datanya homogeny.Setelah itu, pengujian normalitas data dilakukan dengan menggunakan chi kuadrad $\left(\mathrm{X}^{2}\right)$.Perhitungan normalitas data secara lengkap dapat dilihat pada Tabel 3.

Tabel 3 Hasil Uji Normalitas

\begin{tabular}{ccc}
\hline Variasi & Kecakapan Personal & Kemampuan Literasi Sains \\
\hline$X_{\text {hitung }}^{2}$ & 4,20 & 9,02 \\
$X_{\text {tabel }}^{2}$ & 11,07 & 11,07 \\
Kriteria & Data berdistribusi normal & Data berdistribusi normal
\end{tabular}

Berdasarkan Tabel 3 dapat hasil perhitungan yang dilakukan, diketahui data berdistribusi normal dan diperoleh persamaan regresi $\hat{Y}=1,006 X-$ homogen sehingga dapat dilanjutkan 10,17. Data uji regresi linear sederhana pengujian hipotesis dengan menggunakan dapt dilihat pada Tabel 4.

uji regresi linear sederhana.Berdasarkan

Tabel 4 Uji Regresi Kecakapan Personal Terhadap Kecakapan Personal

\begin{tabular}{lll}
\hline Uji Regresi & Literasi Sains \\
\hline $\begin{array}{l}\text { Persamaan regresi } \\
\text { Keberartian dan } \\
\text { persamaan regresi }\end{array}$ & $\hat{\mathrm{Y}}=1,006 \mathrm{X}-10,17$ \\
& & $\mathrm{~F}$ hitung $=11,88$ \\
& & $\mathrm{~F}$ tabel $=4,225$ \\
Koefisien korelasi $\quad\left(\mathrm{r}_{\mathrm{xy}}\right) \quad$ dan & $\begin{array}{l}\text { Kriteria }=\text { signifikan } \\
\text { determinasi }\left(\mathrm{r}^{2}\right)\end{array}$ & $\begin{array}{l}\mathrm{r}_{\mathrm{xy}}=0,56 \\
\mathrm{r}^{2}=0,31 \\
\text { Uji keberartian koefisien korelasi } \\
\end{array}$ \\
& $\mathrm{t}$ hitung $=3,446$ \\
& $\mathrm{t}$ tabel $=2,06$ \\
\hline
\end{tabular}


Kriteria $=$ signifikan

Berdasarkan Tabel 4 dapat diketahui bahwa jika $\mathrm{X}=0$ (kecakapan personal tidak ada), maka diperoleh skor $\hat{Y}$ sebesar -10,17. Hal ini menunjukkan bahwa nilai $\hat{Y}$ tidak hanya dipengaruhi oleh kecakapan personal saja, tetapi ada faktor lain yang mempengaruhinya, seperti motivasi dan minat belajar, keterampilan sosial, sarana dan prasarana belajar, keahlian guru dalam mengajar, iklim sosial dalam kelas, karakteristik belajar, dan faktor eksternal lainnya. Hasil tersebut sesuai dengan Heath, et al (2014) yang menyatakan bahwa literasi sains dipengaruhi oleh faktor eksternal seperti status sosial, sejarah keluarga dan pendidikan orang tua. Selain itu,persamaan regresi pada Tabel 4 menunjukkanbahwa jika kecakapan personalditingkatkan satu skor, makaratarata skor literasi sains akan meningkat sebesar 1,006.

Setelah didapatkan persamaan regresi, selanjutnya dilakukan uji keberartian dan kelinieran regresi linier sederhana untuk mengetahui pengaruh antara variabel kecakapan personal terhadap kemampuan literai sains.Berdasarkan perhitungan dapatdiketahui bahwa persamaan garis tersebut linier, yang berarti bahwa $\mathrm{X}$ mempunyai hubungan linier terhadap $\mathrm{Y}$ sehingga dapat disimpulkan bahwa kecakapan personal berpengaruh secara positif terhadap kemampuan literasi sains siswa. Hubungan positif ditunjukkan oleh tanda positif pada koefisien regresi (1,006).Deryati, dkk (2013) meyimpulkan bahwa terdapat pengaruh yang positif dan signifikan antara keterampilan berkomunikasi sains dengan menggunakan pendekatan multiple representations terhadap literasi sains siswa. Selain itu, motivasi belajar, kedisiplinan belajar berpengaruh terhadap hadir belajar siswa. Semakin baik hasil belajar siswa, maka semakin baik pula literasi sains siswa (Kusuma, 2015).

Berdasarkan Tabel 5diperoleh koefisien korelasi $\left(\mathrm{r}_{\mathrm{xy}}\right)$ sebesar 0,56. Menurut Kariadinata\& Abdurrahman (2012), nilai $r_{x y}$ inimenunjukkan tingkat hubungan yang sedang atau baik antara kecakapan personal (X) terhadap kemampuan literasi sains (Y).Salah satu hal yang berkaitan dengan kecakapan personal adalah self regulated learning. Affandi (2015) menyimpulkan bahwa self regulated learning siswa berpengaruh secara positif dan signifikan terhadap kemampuan literasi sains. Selain itu, pembelajaran berbasis literasi sains dapat meningkatkan hasil belajar siswa (Haristy, 2013).

Selain itu, diperoleh perhitungan koefisien determinasi $\left(\mathrm{r}^{2}\right)$ sebesar 0,31 atau $31 \%$. Nilai tersebut menunjukkan bahwa $31 \%$ kemampuan literasis sains dipengaruhi oleh kecakapan personal, sedangkan $69 \%$ dipengaruhi oleh faktor lain. Tahap akhir yang dilakukan adalah pengujian keberartian koefisien korelasiuntuk mengetahui besarnya pengaruh kecakapan personal (X) terhadap kemampuan literasi sains (Y). Berdasarkan analisis data diketahui bahwa terdapat pengaruh yang signifikan antara kecakapan personal terhadap kemampuan literasi sains siswa. Sebaran data analisis uji regresi yang dilakukan dapat dilihat pada Grafik 1. 


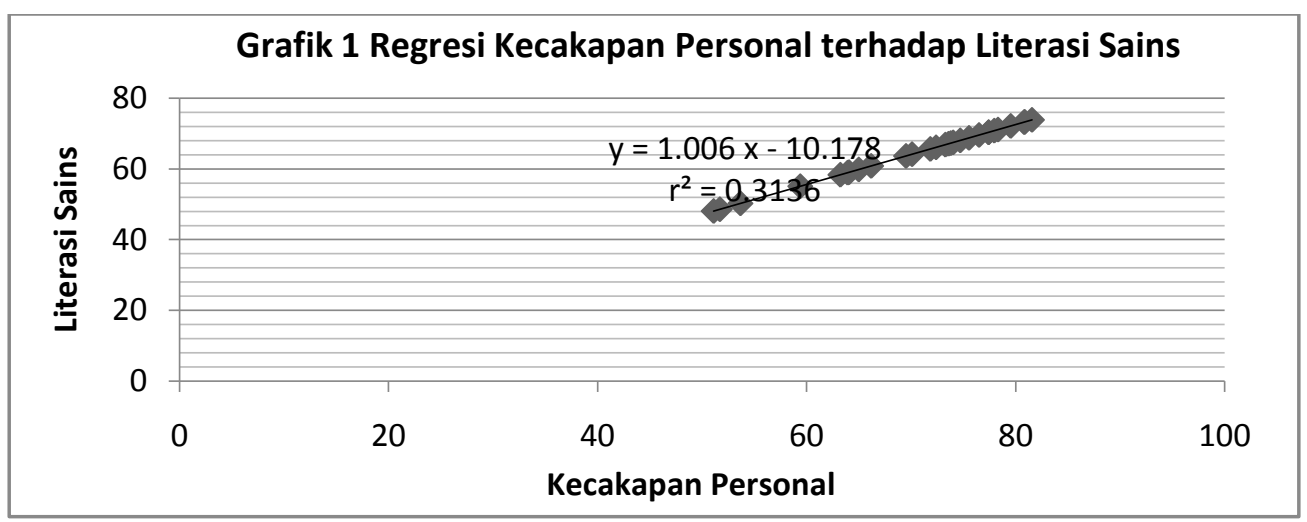

Berdasarkan Grafik 1, besarnya pengaruh kecakapan personal terhadap literasi sains pada setiap siswa berbeda. Hal ini terlihat dari bentuk grafik yang miring dan merata, artinya bahwa sebagian besar siswa yang mempunyai kecakapan personal dengan baik akan mempunyai kemampuan literasi sains dengan baik pula.Kecakapan personal berkaitan dengan faktor internal dari individu. Hasil belajar individu dipengaruhi oleh faktor internal dan eksternal. Begitu juga dengan literasi sains, dipengaruhi oleh banyak faktor, diantaranyasikap siswa, latar belakang pendidikan orang tua, strategi problem based learning, kegiatan belajar mengajar di kelas, latar belakang pendidikan orang tua, waktu yang digunakan untuk belajar sains, kepercayaan-diri dan motivasi belajar (Ekohariadi, 2009).

\section{SIMPULAN DAN SARAN}

Berdasarkan analisis data dan pengujian hipotesis yang dilakukan, dapat disimpulkan bahwa terdapat pengaruh yang signifikan antara kecakapn personal (X) dengan kemampuan literasi sains (Y).Hal ini berarti bahwa semakin tinggi tingkat kecakapn personal, semakin tinggi pula kemampuan literasis sains siswa.Nilai koefisien korelasi $\left(\mathrm{r}_{\mathrm{xy}}\right)$ sebesar 0,56 diketahui bahwa terdapat hubungan yang positif dalam taraf sedang antara kecakapn personal dengan kemampuan literasi sains. Selain itu, nilai koefisien determinasi $\quad\left(\mathrm{r}^{2}\right) \quad$ sebesar 0,31 menunjukkan bahwa 31\% kemampuan literasi sains dipengaruhi oeh kecakapan personal melalui hubungan linier, sedangkan $69 \%$ dipengaruhi oleh faktor lain.

Kecakapan personal yang diteliti hendaknya meliputi semua indicator dalam kecakapan personal menurut Depdiknas (2006).Tetapi karena keterbatasan, maka peneliti hanya mengukur beberapa indikator.Waktu penelitian sebaiknya juga diperhatikan agar diperoleh skor kecakapan personal yang valid dan reliable.Selain itu, diperlukannya pembelajaran yang variatif yang disesuaikan dengan karakter siswa dan materi pelajaran yang disajikan agar diperoleh hasil yang maksimal serta diperlukannya banyak instrumen agar diperoleh hasil kecakapan personal yang valid.

\section{DAFTAR PUSTAKA}

Affandi, Y. 2015. Pengaruh Self Regulated Learning Siswa Terhadap Literasi Sains Melalui Pembelajaran Inkuiri Terbimbing. Jurnal Pembelajaran Fisika, 3(2): 87-98.

Anggraini, G. Analisis Kemampuan Literasi Sains Siswa SMA Kelas $\mathrm{X}$ di Kota Solok. Prosiding Mathamatics And Sciences Forum 2014.

Balitbang Kemdikbud. 2012. Survei Internasional PISA (Programme 
for International Student Assessment).Puspendik di tulis pada 20 Desember 2012, Online.Tersedia di http://litbang. kemdikbud.go.id/index.php/survei -internasional-pisa. [diakses 2812-2012]

Balitbang Kemdikbud. 2012. Survei Internasional PISA. Online.Tersedia di http://litbang. kemdikbud.go.id/index.php/penila ian/survei-internasional-pisa.

[diakses 1-2-2012]

Bybee, R. W. 2009. PISA'S 2006 Measurement of Scientific Literacy: An Insider's Perspective for the U.S. Science Forum and Science Expert Group PISA 2006 Science. A Presentation for the NCES PISA Research Conference, 2 June. Washington, DC.

Depdiknas.2006. Pengembangan Model Pendidikan Kecakapan Hidup. Jakarta: Puskur Balitbang Depdiknas.

Deryati, dkk. 2013. Pengaruh Keterampilan Berkomunikasi Sains Menggunakan Pendekatan Multiple Representations Terhadap literasi Sains Siswa. Jurnal Pembelajaran Fisika, 1 (2): 67-77.

Ekohariadi. 2009. Faktor-faktor Yang Mempengaruhi Literasi Sains Siswa Indonesia Berusia 15 Tahun. Jurnal Pendidikan Dasar, 10(1): 29-43.

Haristy, dkk.2013. Pembelajaran Berbasis Literasi Sains Pada Materi Larutan Elektrolit dan Non Elektrolit di SMA Negeri 1 Pontianak.Jurnal Pendidikan dan Pembelajaran, 2(12): 1-13.
Heath, et al. 2014. A Spotlight on Preschool: The Influence of Family Factors on Children's Early Literacy Skills. Journal Of Plos One, 9 (4): 1-14.

Holbrook \& Rannikmae. 2009. The Meaning of Scientific Literacy. International Journal of Environmental \& Science Education, 4 (3): 275-288.

Hoolbrook, J. \& Rannikmae, M. 2007. Nature of Science Educaion For Enhancing Scientific Literacy. International Journal Of Science Eduction, 29(11): 1347-1362

Hoolbrook, J. \& Rannikmae, M. 2007. Nature of Science Education For Enhancing Scientific Literacy. International Journal of Science Education, 29(11): 1347-1362.

Kariadinata, R. dan Abdurrahman, M. 2012. Dasar-Dasar Statistik Pendidikan. Bandung: Pustaka Setia.

Kusuma, L. 2015. Pengaruh MOtivasi Belajar dan Kedisiplinan Terhadap Prestasi Belajar Mata Pelajaran Akuntansi Siswa Kelas XI IPS SMA N 3 Pati Tahun Pelajaran 2013/2014.Economic Education Analysis Journal, 4(1): 164-171.

New Zealand Curiculum Guides. 2013. Senior Scondary Science. Wellington: Ministry of Education

Permendiknas. 2006. Peraturan Menteri Pendidikan Nasional Republik Indonesia Nomor 22 Tahun 2006 Tentang Standar Kompetensi Lulusan Untuk Satuan Pendidikan Dasar Dan Menengah. Jakarta: Biro Hukum 
Dan Organisasi, Departemen

Pendidikan Nasional.

Rahayu, S. 2014. Menuju Masyarakat Berliterasi Sains: Harapan dan Tantangan Kurikulum 2013. Makalah disampaikan dalam Seminar Nasional Kimia dan Pembelajarannya 2014 dengan tema "Inovasi Pembeljaran Kimia dan Perkembangan Riset Kimia" di jurusan FMIPA Universitas Malang Tanggal 6 September 2014.

Rychen, D.S. \& Salganik, L.H. 2003.Key Competencies For a Successful Life And a Well Functioning Society. Cambridge, MA: Hogrefer \& Huber. 